JGG 2021;69:14-18

doi: 10.36150/2499-6564-432

\title{
Psychometric properties of the Persian version of the 27-item Elderly Attitude Questionnaire on End-of-Life Issues
}

\author{
Reza Norouzadeh ${ }^{1}$, Mohammad Reza Heidari ${ }^{1}$, Seyedeh Navabeh \\ Hosseinkhani ${ }^{1}$, Anoshirvan Kazemnejad² \\ ${ }^{1}$ Department of Nursing, Faculty of Nursing and Midwifery. Shahed University, Tehran, Iran; \\ ${ }^{2}$ Department of Biostatistics, Faculty of Medical Sciences, Tarbiat Modares University, Tehran, Iran
}

Received: January 24, 2020

Accepted: November 2, 2020

\section{Correspondence \\ Mohammad Reza Heidari \\ Department of Nursing, Faculty of Nursing and Midwifery. Shahed University, Opposite Holy Shrine of Imam Khomeini, Khalij Fars Expressway, Tehran, Iran, P.0.Box 18155/159, Postal/ZIP 3319118651. Tel: +98(21) 51212146. E-mail: mheidari@shahed.ac.ir \\ Conflict of interest \\ The Authors declare no conflict of interest}

\section{Funding}

This research received no specific grant from any funding agency in the public, commercial, or not-for-profit sectors

How to cite this article: Norouzadeh $\mathrm{R}$, Heidari MR, Hosseinkhani SN, et al. Psychometric properties of the Persian version of the 27-item Elderly Attitude Questionnaire on End-of-Life Issues.Journal of Gerontology and Geriatrics 2021;69:14-8. https://doi.org/10.36150/2499-6564-432

C Copyright by Società Italiana di Gerontologia e Geriatria (SIGG)

\section{(c) (1) () (}

\section{OPEN ACCESS}

This is an open access article distributed in accordance with the CC-BY-NC-ND (Creative Commons Attribution-NonCommercial-NoDerivatives 4.0 International) license. The article can be used by giving appropriate credit and mentioning the license, but only for non-commercial purposes and only in the original version. For further information: https://creativecommons.org/licenses/by-nc-nd/4.0/deed.en
Background \& aims. Elderly people have different issues at the end of their lives. This study was conducted to analyze the psychometric properties of the Persian version of Attitudes of Older People to End of Life Issues (AEOLI) questionnaire.

Methods. 189 elderly people participated in this descriptive study. Face, content and construct validity and reliability were assessed for determining the psychometric characteristics of the questionnaire. Construct validity was determined by exploratory factor analysis using principal component analysis with varimax rotation.

Results. The results of this study indicate that the questionnaire has an appropriate face and content validity. Internal consistency (Cronbach's alpha $=0.78, I C C=0.729$ ) showed a good reliability for the questionnaire. Factor analysis showed the nine items of the questionnaire can measure the attitude of the elderly toward end-of-life issues.

Conclusions. The findings of this study showed that the Persian version of the 27-item questionnaire of the elderly attitude toward end-life issues has good validity and reliability.

Key words: psychometrics, elderly, attitude, end-of-life

\section{INTRODUCTION}

Aging is an inevitable process in life ${ }^{1}$. Most developed countries have accepted the age of 65 years and developing countries that of 60 years to be considered as elderly. Currently, 4.5 million of the total population of Iran is over 60 years old ${ }^{2}$ and by 2027 , the number of elderly people is projected to reach 15 million ${ }^{3}$. Chronic illnesses, loneliness, a lack of social support and emotional problems at the end of life (EOL) in the elderly are issues that underline the importance of dying in this age group despite the increased life expectancy 4,5 .

Most researches on older people's attitudes to death and dying is about fear, worry of dying or accepting suffering at the end-of-life ${ }^{6,7}$. for instance, a study shows the elderly not only had faced more death and funerals but they were more likely to think about their own death and dying and more likely to fear death ${ }^{8}$. The importance of focusing on measurement questionnaires in this subject is that the elderly attitude to death can profoundly effect on their mental health and quality of life. As studies have shown, there has been an increase in the incidence of depression, anxiety, and suicide in the elderly with irrational attitudes to end-of-life issues ${ }^{9}$. Also, 
the attitude of the elderly regarding death and dying can overshadow their caring preferences at the end of life; such as the attitude to comfort care than life-saving treatment ${ }^{10}$. Therefore, health care providers to optimal care and support older people's decisions about end of life ${ }^{11}$ must have sufficient knowledge, a sound understanding of the end-of-life priorities as well as older people's attitude to death ${ }^{12}$. To achieve this, we need a culturally specific questionnaire adapted for the Iranian elderly. Existing questionnaire rarely address elderly attitudes to EOL issues and are more in line with elders' whishes to end-of-life care ${ }^{13,14}$. The literature review shows there is only one special questionnaire has been designed by Catt \& Blanchard (2005) to assess the attitudes of older people to end-of-life issues ${ }^{15}$. In any case, this questionnaire is consistent with the beliefs of the elderly in European society. Although there are common concepts in attitudes toward death between Persian and western cultures (i.e., after-death judgment and redemption/downfall, end of life rituals, religiousbased belief in the sanctity of life, condemning suicide) ${ }^{16}$, but there are diversities among Iranian people attitudes to death in realistic and natural acceptance of death, avoidance, and fear of death. For example, belief that 'death is a way to enter the eternal place'; 'death brings peace that does not exist in this world', 'death as a way to get rid of the problems', and 'apocalyptic acceptance of death; the belief that the spirit lives on after death and is transferred to the resurrection' ${ }^{17}$. Such attitudes are inspired by the verses of the Qur'an and Islamic traditions about the nature of death ${ }^{18}$. In different parts of the Qur'an, the subject of death is discussed. Death is inevitable and no one can escape it. In this case, the Qur'an says in Surah 50, verse 19 "And the intoxication of death will bring the truth; that is what you were trying to avoid ". Also in Sura 67, verse 2 says: "He (Allah) who created death and life, so that He may test you as to which of you is better in deeds. And $\mathrm{He}$ is the All-Mighty, the Most-Forgiving".

The importance of assess the attitudes of older people to end-of-life issues and lack of a reliable and valid questionnaire for this subject in Iran, prompted the researchers to study the psychometric properties of the Persian version of the elderly attitudes to the end of life issues.

\section{MATERIALS AND METHODS}

In this descriptive study, validity and reliability of Attitudes of Older People to End-of-Life Issues (AEOLI) questionnaire was evaluated. The study population consisted of the elderly. Subjects were evaluated for age, gender, education, employment status, marital status, and hospitalization history. 189 elderly from Elderly Centers were selected by random sampling in 4 districts (North, South, East and West) of Tehran city, 2018. Elderly Centers (Jahandidegan Centers), which are located in the city of Tehran, is a place where cultural and artistic classes, recreational tours and tourism are held along with social activities and charitable activities for the elderly. Through these centers, which are run by the elderly, the most important physical, psychological and social problems of the elderly are identified. Data collecting instrument consisted of the Attitudes of Older People to End of Life Issues (AEOLI) questionnaire and elderly demographic data sheet (including: age, gender, education, employment status, marital status, and hospitalization history). AEOLI questionnaire consist of 9 domains and 27 items including decision making (item 1), pain (items 5, 9, 20), care environment (items $3,6,10,15,27$ ), living wills (items 8, 14, 19, 24), euthanasia (items 4, 17, 18, 26), ageism (items 13, 16, 23), psychological needs including religious/spiritual (items 11,25 ), quality versus quantity of life (items 2, 7, 21, 22) and societal awareness (items 12). The questionnaire is scored on a 5-point Likert scale (strongly agree $=5$, agree $=4$, neutral $=3$, disagree $=2$ and strongly disagree $=1$ ). The highest score is 135 and the lowest score is 27.

\section{VALIDITY AND RELIABILITY}

Permission was obtained from the designer of the questionnaire to begin the translation and psychometric process of the questionnaire. Forward-backward method was used to translate the questionnaire into Farsi (Persian).The questionnaire was first returned to Persian by two experts and a Persian version was prepared. The translated version was independently translated into English by two other individuals and was compared with the original and final version.

\section{VALIDITY}

The validity of the questionnaire was assessed in three stages: face, content, and construct validity.To determine face validity, 10 elders were asked to comment on readability, writing clarity, easy understanding and ease of completing the questionnaire items. In qualitative content validity method, content experts and target group's recommendations are adopted on observing grammar, using appropriate and correct words, applying correct and proper order of words in items and appropriate scoring ${ }^{19}$. So, to determine the qualitative content validity, 5 people with knowledge and experience in the subject of the questionnaire were asked to rate about the language, appropriate words, appropriate place of the items, and clarity, simplicity, 
transparency and relevancy. The construct validity was assessed through factor analysis. The main instrument has nine domains and exploratory factor analysis was used to determine its possible dimensions.

\section{RELIABILITY}

Cronbach's alpha coefficient ${ }^{20}$ was used to evaluate internal consistency $(\alpha=0.78)$. In this study, coefficient being above 0.7 has been considered acceptable. Also, the questionnaire was given to 20 elders in two weeks interval and intrarclass correlation coefficient was calculated between two time periods indicated good reproducibility $(\mathrm{ICC}=0.72, \mathrm{p}<0.001, \mathrm{Cl}=0.521-0.874)$.

\section{Data analysis}

Descriptive statistics (mean and standard deviation) was used to summarize demographic and clinical findings. Construct validity was determined by exploratory factor analysis using SPSS software (version 16). Kaiser-Meyer-Olkin (KMO) test was used to determine the adequacy of selected sample size for factor analysis. The Varimax rotation method was used to estimate the main components of analysis.

\section{ETHICAL CONSIDERATIONS}

After approving the research topic in research ethics committee (IR.Shahed.REC.1394.287), by submitting a written letter, the researcher has introduced himself to the elders and obtained their written permission. The research objective and the steps and processes are explained in detail to the elders and they have been assured of the confidentiality of all the information. It has also been explained to all elders that their participation in this research is optional and they had right to withdraw and any stage of the research.

\section{RESULTS}

The mean age of the elders was $67.75 \pm 5.69$ years. Of the 189 elderly, 132 (69.8\%) were women, 137 (72.5\%) were married, 86 (45.5\%) were retired, and 109 (57.7\%) were illiterate. Because we had no assumptions about the dimensions of the questionnaire, exploratory factor analysis was used to determine the alternative structure of the questionnaire. Varimax rotation was used after performing principal component extraction to check how many factors saturated the questionnaire. The calculated value of $\mathrm{KMO}$ was 0.90 indicating the sampling adequacy. The Kaiser-Meier-Olekin (KMO) statistic is considered to be 0.8 or higher. The Bartlett Spherical Test was significant (Chi-square $=1491.6291, p=0.000$ ) indicating the presence of correlations among variable and the ability of the questionnaire to perform factor analysis (Tab. I). The correlation coefficients of the variables with each factor (factor loads) after rotation and ten extracted factors with eigenvalue $>1$ are shown in Table II. Factors 1 to 10 can explain $67.91 \%$ of the total variance. The extracted factors were rotated using varimax rotation method and factor(s) with factor load $\geq 0.30$ included in analysis. Field in his book says "Typically, researchers take a loading of an absolute value of more than 0.3 to be important" ${ }^{21}$.

Table I. Bartlett Spherical Test and KM0.

\begin{tabular}{|l|c|c|c|}
\hline \multicolumn{1}{|c|}{ KM0 Test } & \multicolumn{3}{|c|}{ Bartlett Spherical Test } \\
\hline Sample adequacy & $\mathrm{P}$ & Degree of freedom & $\mathrm{X}^{2}$ \\
\cline { 2 - 4 } 0.8 & 0.000 & 351 & 1491.621 \\
\hline
\end{tabular}

Table II. Extracted factors.

\begin{tabular}{|c|c|c|c|c|c|c|}
\hline \multicolumn{3}{|c|}{ Sum of the factor coefficients after rotation } & \multicolumn{3}{|c|}{ Initial special values } & \multirow[t]{2}{*}{ Items } \\
\hline $\begin{array}{c}\text { Cumulative } \\
\text { frequency (\%) }\end{array}$ & $\begin{array}{c}\text { Variance } \\
\text { (\%) }\end{array}$ & Total & $\begin{array}{c}\text { Cumulative } \\
\text { frequency (\%) }\end{array}$ & $\begin{array}{c}\text { Variance } \\
\text { (\%) }\end{array}$ & Total & \\
\hline 14.235 & 14.235 & 3.843 & 17.418 & 17.418 & 4.703 & 1 \\
\hline 21.433 & 7.198 & 1.943 & 27.124 & 9.706 & 2.621 & 2 \\
\hline 28.071 & 6.638 & 1.792 & 34.449 & 7.325 & 1.978 & 3 \\
\hline 34.434 & 6.363 & 1.718 & 40.754 & 6.306 & 1.702 & 4 \\
\hline 40.644 & 6.210 & 1.677 & 46.595 & 5.841 & 1.577 & 5 \\
\hline 46.567 & 5.922 & 1.599 & 51.398 & 4.802 & 1.297 & 6 \\
\hline 52.399 & 5.832 & 1.575 & 55.838 & 4.441 & 1.199 & 7 \\
\hline 58.030 & 5.631 & 1.520 & 59.987 & 4.149 & 1.120 & 8 \\
\hline 63.150 & 5.119 & 1.382 & 64.117 & 4.130 & 1.115 & 9 \\
\hline 67.912 & 4.762 & 1.286 & 67.912 & 3.795 & 1.025 & 10 \\
\hline
\end{tabular}


So, we used suppressing factor loadings less than 0.3. Using the factor matrix of items, the factor loadings of each item were compared in the 10 extracted factors, and each item was subjected to the factor with the highest factor loading. The first factor (items 1,6,9,10,12 and 21), the second factor (items 2 and 14), the third factor (items 23, 26 and 27), the forth factor (items 3, 4 and 5), the fifth factor (items 7, 15 and 24), factor 6 (items 22 and 25), factor 7 (items 16 and 17), factor 8 (items 8,11 and 13), factor 9 (items 19 and 20), and factor 10 (items 18). However, the main questionnaire has 9 domains: decision making (item 1), pain (items 5, 9 and 20), care environment (items $3,6,10,15$ and 27), living wills (items 8 , $14,19,24)$, euthanasia (items 4, 17, 18, 26), aging (items 13, 16 and 23), psychological needs including religious/ spiritual (items 11 and 25), quality of life vs quantity of life (items 2, 7, 21 and 22) and societal awareness (item 12). After careful examination of the items it was found due to the inconsistency of some of the items with the most frequently occurring factor, the created factors could not be named based on the nature of their items. Since, factor analysis was not able to identify the items and put them in the related factor, the hypothesis of the questionnaire with nine domains and item placement in each domain is confirmed. So, the items together measure the attitude of the elderly toward end-of-life issues.

\section{DISCUSSION}

There are no studies on end-of-life care preferences among Iranian elderly and there is insufficient information on attitudes and preferences in end of life issues among the elderly population. The Attitudes of Older People to End-of-Life Issues (AEOLI) developed in the UK is related to attitude and preparedness for death and preferences about the place of care. The present study aimed to translate and investigate the characteristics of the questionnaire. A review of the literature showed that only one study in China by Law (2014) has been conducted to translate this questionnaire and examine its characteristics. In some studies, the questionnaire has been used, which does not indicate its validity or reliability. The Chinese version of the AEOLI questionnaire was prepared and evaluated for some psychometric properties. Reliability test was performed on 12 men and 38 women 65 to 95 years (mean, 84.1, standard deviation, 6.6 years). The weighted Kappa ranged from 0.61 to 1.00 , indicating moderate to excellent consistency. The CVI was 0.83 , indicating a high level of agreement among experts regarding relevance. Face validity confirmed that the content of the Chinese AEOLI questionnaire reflects the concepts the researcher intends to measure ${ }^{22}$. Catt \& Blanchard (2005) developed a questionnaire to assess the attitudes of older people toward end-of-life problems. Using systematic keywords in databases such as Index medicus/ Medline, EMBASE, Pschinfo and CINAHL, he systematically searched for questionnaires and related articles about the attitude of the elderly toward end of life. These questionnaires were less commonly used in the field of aging. According to the results, Cronbach's alpha in living wills was $0.68 \%$, euthanasia was 0.77 , and quality of life vs. quantity of life was $0.52^{15}$. Also, the McCarthy (2010) have used AEOLI questionnaire in a national survey to determine understanding and views of Irish adults about of ethical issues to death and dying. A list of six statements about attitude to certain aspects of death and dying were read for participants. People were most concerned about their quality of dying and believed if they were no hope of recovery because of a serious illness, their quality of life is more important than how long it lasted. At the same time, older people gave more value on length of life ${ }^{23}$. Gauthier and Froman (2001) developed and validated the preferences for care near the end of life (PCEOL). A sample of 198 adults was used for psychometric evaluation of the instrument. Data screening and item analysis resulted in 43 items. Factor analysis indicated a meaningful and interpretable 5-factor solution. The multidimensional internal consistency of the instrument ranged from 0.68 to 0.91 . Test - retest consistency showed a correlation of 0.80 to 0.94 for factor scores over a two-week interval. Although the questionnaire addresses end-of-life issues, it only examines the multidimensional nature of the endof-life preferences. The AEOLI questionnaire contains areas of decision making, pain, care environment, living wills, euthanasia, aging, psychological needs (religious/ spiritual), quality of life versus quantity of life, and societal awareness. PCEOL includes autonomy in physiological and health care decision making, spirituality, family, and emotional communication. There are similarities and differences between the titles of the domains and items ${ }^{24}$. Schirm (2008) examined the psychometric evaluation of the PCEOL questionnaire developed by Gauthier and Forman that determines the dimensions of end-of-life care during a series of 68 workshops on a sample of nurses, nursing students, nursing assistants, and the elderly. Respondents were asked to state their personal preferences in terms of their values. The findings of this study support and recommend the use of the questionnaire in nursing care based on a three-factor structure; individual autonomy, health providers, spirituality, and family ${ }^{25}$.

Given that the elderly have many concerns about end-of-life issues, this questionnaire can be helpful in understanding their attitudes. The authors conclude that the psychometric evaluation of the Persian version of the Elderly Attitude Questionnaire to End-of-Life 
issues show that the Persian versions of this standard instrument has sufficient reliability and validity for use in Persian-speaking Iranian elderly. Further studies are recommended to use this questionnaire in larger samples. One of the limitations of this study is that it cannot be generalized to the hospitalized elderly.

\section{ACKNOWLEDGEMENTS}

This study was approved by the Ethics Committee of Shahed University. The authors would like to express our sincere gratitude to the respected authorities of elderly health centers and the elderly people who have collaborated on this research.

\section{References}

1 Singh S, Bajorek B. Defining 'elderly'in clinical practice guidelines for pharmacotherapy. Pharmacy Pract 2014;12. https://doi.org/10.4321/s1886-36552014000400007

2 Bavardi Moghadam E, Shojaedin SS, Radfar H. Effect of pilates training on functional balance of elderly men. Journal of Gorgan University of Medical Sciences 2018;20:64-9.

3 Afshar PF, Asgari P, Shiri M, et al. A review of the Iran's elderly status according to the census records. Galen Medical Journal 2016;5:1-6.

4 Lorenz KA, Lynn J, Dy SM, et al. Evidence for improving palliative care at the end of life: a systematic review. Annals of internal medicine 2008;148:147-59. https://doi. org/10.7326/0003-4819-148-2-200801150-00010

5 Qaseem A, Snow V, Shekelle P, et al. Evidence-based interventions to improve the palliative care of pain, dyspnea, and depression at the end of life: a clinical practice guideline from the American College of Physicians. Annals of internal medicine 2008;148:141-6. https://doi.org/10.7326/00034819-148-2-200801150-00009

6 Lockhart LK, Bookwala J, Fagerlin A, et al. Older adults' attitudes toward death: links to perceptions of health and concerns about end-of-life issues. OMEGA-Journal of Death and Dying 2001;43:331-47. https://doi. org/10.2190/09B5-CCWE-D5GA-FOMA

7 Depaola SJ, Griffin M, Young JR, et al. Death anxiety and attitudes towardthe elderly among older adults: the Role of gender and ethnicity. Death Studies 2003;27:335-54.

8 Kalish RA, Reynolds DK. The role of age in death attitudes. Death Studies 1977;1:205-30.

9 Basharpoor S, Hoseinikiasari ST, Soleymani E, et al. The role of irrational beliefs and attitudes to death in quality of life of the older people. Iranian Journal of Ageing 2019;14:260-71.

10 Fleming J, Farquhar M, Brayne C, et al.; Collaboration CCO-sCS. Death and the oldest old: attitudes and preferences for end-of-life care-qualitative research within a population-based cohort study. PloS One 2016;11. https://doi.org/10.1371/journal.pone.0150686

11 Catt S, Blanchard M, Addington-Hall J, et al. Older adults' attitudes to death, palliative treatment and hospice care. Palliative medicine 2005;19:402-10. https://doi. org/10.1191/0269216305pm1037oa

12 Matsui M, Braun KL. Japanese Americans' death attitudes and preferences for end-of-life care. Journal of Hospice \& Palliative Nursing 2009;11:353-61. https://doi. org/10.1097/NJH.0b013e3181bd03f1

13 Srinonprasert V, Kajornkijaroen A, Bangchang PN, et al. A survey of opinions regarding wishes toward the end-oflife among Thai elderly. J Med Assoc Thail 2014;97(Suppl 3):S216-22.

14 Yamaguchi $\mathrm{Y}$, Mori $\mathrm{H}$, Ishii M, et al. Interview and questionnaire based surveys on elderly patients' wishes about artificial nutrition and hydration during end of life care. Geriatr Gerontol Int 2016;16:1204-10. https://doi.org/10.1111/ ggi.12615

15 Catt S, Blanchard M, Addington-Hall J, et al. The development of a questionnaire to assess the attitudes of older people to end-of-life issues (AEOLI). Palliative medicine 2005;19:397-401. https://doi. org/10.1191/0269216305pm1036oa

16 Aramesh K. History of attitudes toward death: a comparative study between Persian and western cultures. Journal of medical ethics and history of medicine 2016;9:20.

17 Cheraghi MA, Payne S, Salsali M. Spiritual aspects of end-of-life care for Muslim patients: experiences from Iran. International journal of palliative nursing 2005;11:468-74. https://doi.org/10.12968/ijpn.2005.11.9.19781

18 Badawi G. Muslim attitudes towards end-of-life decisions. The Journal of IMA 2011;43:134-9. https://doi. org/10.5915/43-3-8602

19 Safikhani S, Sundaram M, Bao Y, et al. Qualitative assessment of the content validity of the Dermatology Life Quality Index in patients with moderate to severe psoriasis. Journal of dermatological treatment 2013;24:50-9. https://doi. org/10.3109/09546634.2011.631980

20 Waltz CF, Strickland OL, Lenz ER. Measurement in nursing and health research: Springer publishing company 2010.

21 Field A. Discovering statistics using IBM SPSS statistics. Sage 2013.

22 Law N, Luk J, Choi K, et al. Chinese translation of Attitudes of Older People to End of Life Issues Questionnaire. Asian Journal of Gerontology \& Geriatrics 2014;9:74-9.

23 McCarthy J, Weafer J, Loughrey $M$. Irish views on death and dying: a national survey. Journal of Medical Ethics 2010;36:454-8. https://doi.org/10.1136/ jme.2009.032615

24 Gauthier DM, Froman RD. Preferences for care near the end of life: scale development and validation. Research in nursing \& health 2001;24:298-306. https://doi. org/10.1002/nur.1031

25 Schirm V, Sheehan D, Zeller RA. Preferences for care near the end of life: instrument validation for clinical practice. Critical care nursing quarterly 2008;31:24-32. https://doi. org/ 10.1097/01.CNQ.0000306393.79282.5b 